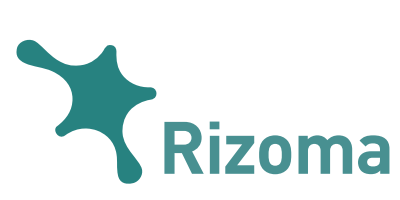

\title{
Futuros presentes:
}

\section{a ficção distópica como reflexo do cotidiano}

\begin{abstract}
Resumo: Este artigo tem por objetivo abordar algumas das relações que o futuro descrito nas ficções distópicas estabelece com questões presentes na vida cotidiana, mais especificamente no contexto das épocas em que tais textos foram escritos. Para alcançar os objetivos propostos, o trabalho trará à baila os conceitos de utopia e distopia, conforme tratados por Thomas Morus e Evanir Pavloski, dialogando com questões propostas por Agnes Heller e Michel de Certeau ao abordar o tema do cotidiano. Tais discussões serão ilustradas pelas obras Nós, de Yevgeny Zamyatin, 1984, de George Orwell, e Jogos Vorazes, de Suzanne Collins, as quais serão abordadas ao longo do artigo.

Palavras-chave: Cotidiano. Futuro. Ficção. Distopia.
\end{abstract}

\section{Futuros presentes: la ficción distópica como reflejo de lo cotidiano}

Resumen: Este artículo tiene por objetivo abordar algunas de las relaciones que el futuro descrito en las ficciones distópicas establece con cuestiones presentes en la vida cotidiana, más específicamente en el contexto de las épocas en que tales textos fueron escritos. Para alcanzar los objetivos propuestos, el trabajo traerá a la baila los conceptos de utopía y distopía, conforme tratados por Thomas Morus y Evanir Pavloski, dialogando con cuestiones propuestas por Agnes Heller y Michel de Certeau al abordar el tema de lo cotidiano. Tales discusiones serán ilustradas por las obras Nosotros, de Yevgeny Zamyatin, 1984, de George Orwell, y de Los Juegos del Hambre, de Suzanne Collins, las cuales serán abordadas a lo largo del artículo.

Palabras clave: Cotidiano. Futuro. Ficción. Distopia.

\section{Present futures: dystopian fiction as a reflection of everyday life}

Abstract: This paper aims to address some of the relationships that the future described in dystopian fictions establishes with issues present in everyday life, more specifically in the context of the times when such

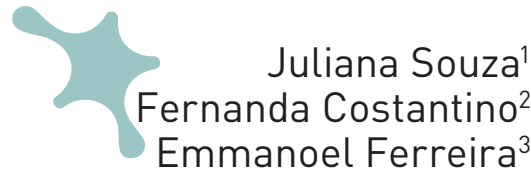

\footnotetext{
1 Mestranda do Programa de Pós Graduação em Mídia e Cotidiano;

2 Mestranda do Programa de Pós Graduação em Mídia e Cotidiano.

3 Doutor em Comunicação, Professor do Departamento de Estudos Culturais e Mídia e do Programa de Pós Graduação em Mídia e Cotidiano.
} 


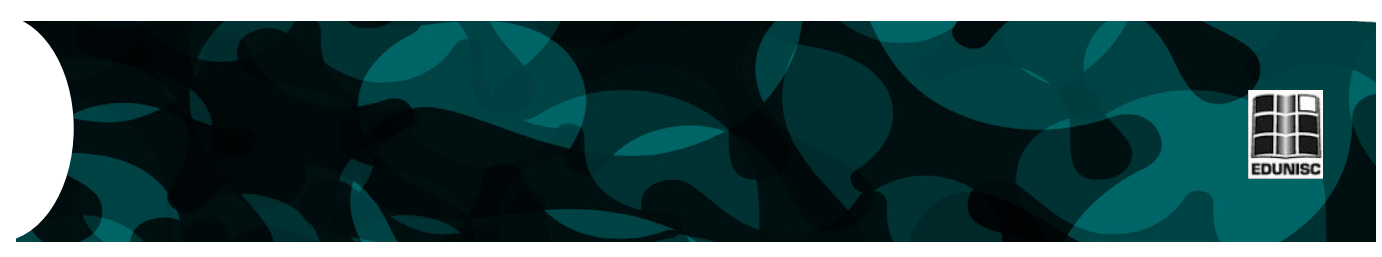

texts were written. In order to reach the proposed objectives, this work will bring to the fore the concepts of utopia and dystopia, as treated by Thomas Morus and Evanir Pavloski, dialoguing with questions proposed by Agners Heller and Michel de Certeau when addressing the subject of everyday life. Such discussions will be illustrated by the works We, by Yevgeny Zamyatin, 1984, by George Orwell and Hunger Games, by Suzanne Collins, which will be discussed throughout the paper.

Keywords: Everyday Life. Future. Fiction. Dystopia.

\section{Introdução}

Em 2016, a revista Bravo! e o jornal digital Nexo publicaram ${ }^{4}$ duas matérias abordando o mesmo tema: a ficção distópica e sua aproximação com a realidade. Por se tratar de algo contrário ao ideal existente no conceito de utopia, a distopia caracteriza-se como um futuro pior do que o presente. Em ambas as matérias, os jornalistas atentaram para o fato de as alusões ficcionais ao futuro não estarem apenas relacionadas com o retrato das incertezas do que está por vir, mas também como uma própria leitura do presente. O texto da Bravo! propõe ao leitor que tente isolar as narrativas do mundo real de modo que seja possível entender o seu sentido e aprender algo a partir das obras de ficção. Já o Nexo, que, por sua vez, conversou com roteiristas e cineastas ${ }^{5}$, propõe um teste com 10 questões que misturam cenários reais e distópicos trazendo apenas duas opções de resposta em cada item, desafiando o leitor a diferenciar a ficção da realidade.

Se olharmos para a cronologia da produção das narrativas distópicas, o livro Nós, escrito entre 1920 e 1921 pelo russo Yevgeny Zamyatin, pode ser considerado pioneiro na temática e traz em sua trama um planeta Terra quase mil anos após os dias atuais. Nesta Terra do futuro, a sociedade vive de acordo com as leis da Matemática, pois ela, segundo o narrador - o personagem D-503, é a ciência mais nobre no que tange à criação de uma ordem perfeita. De acordo com o mesmo narrador, os antepassados (ou seja, os humanos do século XX) viviam em completo caos, algo inaceitável para os padrões de vida da época retratada no livro. Em Nós, todas as ações dos personagens são vigiadas e controladas ao longo do dia, tudo é cronometrado. A única exceção são alguns breves momentos de privacidade aos quais os cidadãos têm direito, geralmente utilizados para encontros amorosos. Além do controle dos corpos e do tempo, há também a ordenação - matemática - daqueles mesmos corpos. Os indivíduos devem se locomover na mais perfeita ordem, alinhados. Não à toa um dos símbolos de maior potência na história é o do quadrado. Para alguns críticos literários, Nós não seria uma obra distópica nos moldes de outras mais conhecidas e estabelecidas ao longo do século $\mathrm{XX}$, pois sua sociedade, ou grande parte dela, via aquela forma de vida como
${ }^{4}$ Matérias publicadas na internet. Link completo nas referências.

5 O diretor e roteirista Jotagá Crema, o escritor e cineasta João Paulo Cuenca e o editor e roteirista de quadrinhos Raphael Fernandes. Link da entrevista nas referências. 


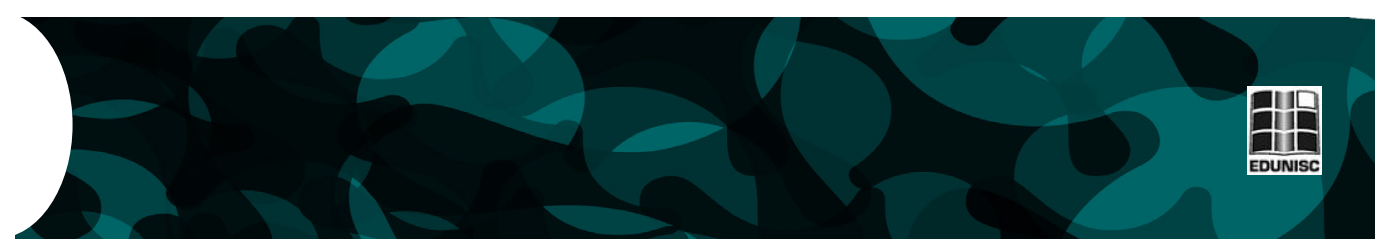

evoluída. Em todo caso, há, ali, uma visível crítica à ordem imposta deliberadamente e ditatorialmente por um governo, e isto ocorre quando o narrador começa a repensar aquele modo de vida.

Talvez de forma mais sutil que as obras que viriam a surgir nos anos e décadas seguintes, Nós abre, de certa forma, o caminho para este gênero da literatura que viria a conhecer grande importância ao longo do século XX e agora no século XXI. Já a obra 1984, escrita por George Orwell, é vista como uma das mais influentes do último século, ao tratar a distopia em um regime totalitário e vigilante. Nos últimos anos, as obras de ficção que abordam a distopia voltaram a ganhar destaque na literatura e no cinema, principalmente diante do público jovem. Responsável por trazer o tema novamente à tona no século XXI, Jogos Vorazes, de Suzanne Collins, desperta o interesse de jovens e adultos ao abordar a distopia em meio a um contexto de resistência e engajamento frente a um governo ditatorial.

Esta retomada das obras de ficção distópicas na literatura e no cinema nos últimos anos pode ser entendida como um reflexo das necessidades do indivíduo de encontrar respostas para o atual contexto da sociedade em que vive. Os filmes contemporâneos de Hollywood, baseados em narrativas distópicas, têm, cada vez mais, apostado em roteiros que reflitam os medos, esperanças, conflitos e ideologias políticas da sociedade americana (KELLNER, 2016). Eles não só apresentam temas ambientais e sociopolíticos como também discutem o futuro da humanidade. Segundo Kellner (2016) esse é o cinema contemporâneo de apocalipse social hollywoodiano. Tais temas surgem para responder aos anseios da sociedade em relação ao cotidiano.

Dentro desta perspectiva tencionamos, neste artigo, abordar algumas das relações que o futuro descrito nas ficções distópicas estabelece com a vida cotidiana. Para alcançar os objetivos propostos neste trabalho, traremos à baila os conceitos de utopia e distopia, conforme tratados por Thomas Morus e Evanir Pavloski, dialogando com questões propostas por Agnes Heller e Michel de Certeau, ao abordar o tema do cotidiano. Tais proposições serão ilustradas pelas obras Nós, de Yevgeny Zamyatin, 1984, de George Orwell, e Jogos Vorazes, de Suzanne Collins, descritas anteriormente, e que serão abordadas ao longo do artigo.

\section{Utopia e distopia: o futuro como locus de reflexão}

Quando Thomas Morus fez uma análise crítica da sociedade inglesa no século XVI, ele apontou na composição social, no aspecto político e na dimensão econômica, fatores responsáveis pela falta de liberdade e diversos problemas da população. Dividida de forma estratificada entre nobres, clero, soldados e os miseráveis, a Inglaterra era governada por um regime absolutista, onde "o príncipe é a fonte de onde o bem e o mal jorram, como uma torrente, sobre o povo" (MORUS, 2004, p. 14) 

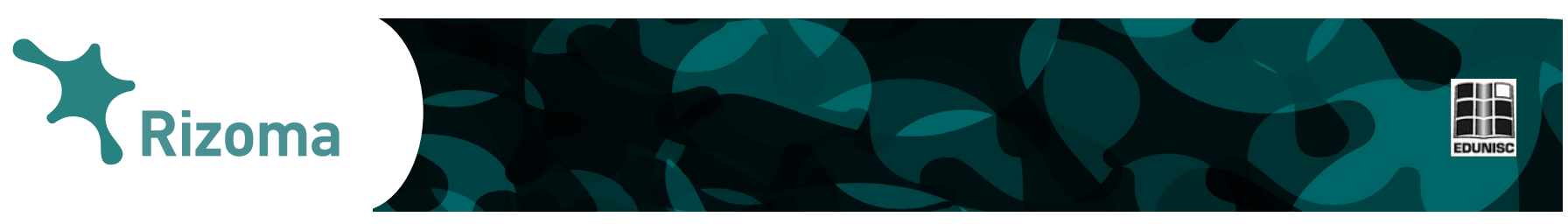

A obra de Thomas Morus e a consequente assimilação da ideia de Utopia também como um gênero textual, abriu caminho para diversas outras produções textuais filosóficas, sociológicas e literárias serem inseridas nesta temática utópica (PAVLOSKI, 2005). Apesar disso, o gênero não se limita apenas ao proposto por Morus, sendo composto por diversos outros aspectos característicos, surgindo exemplos - em uma comparação diacrônica - em obras anteriores ao século XVI como "A República"6, de Platão. Do mesmo modo, o historiador Szachi (1972) atenta para outras propostas que podem ser inseridas nessa temática. Em suas palavras:

Esquemas semelhantes percebemos em casos de 'viagens' no tempo, empreendidas tantas vezes, seja em direção ao legendário 'século de ouro', seja para um futuro que embora não muito claro em seus contornos, é, com certeza, mais feliz. E não será uma 'utopia' o que escreve o político que propõe um projeto de constituição ideal para seu país? (SZACHI, 1972, p. 3)

Foi essa ideia de utopia, cunhada no século XVI, que permitiu nutrir uma visão otimista e esperançosa de um "lugar melhor" no futuro, com formas perfeitas de governo e convivência, apesar de consistir num padrão de sociedade jamais vivido ou alcançado. Para o crítico literário Swietochowski (apud SZACHI, 1972), representar uma forma ideal das relações sociais é um desejo inerente de qualquer época, nação ou até mesmo um indivíduo. É ele a dizer:

\footnotetext{
A utopia como a forma ideal de relações sociais é elemento o mais generalizado no mundo espiritual. Faz parte de todas as crenças religiosas, teorias morais e legais, sistemas de educação, criações poéticas, em uma palavra, de todo conhecimento e obra que visam oferecer modelos para a vida humana. É impossível imaginar qualquer época, nação ou mesmo indivíduo que não tenha sonhado com um céu na terra, que não tenha sido mais ou menos utópico. Onde quer que existam - e elas existem em toda parte - miséria, injustiça e dor, haverá também especulações sobre como erradicar as causas do mal. Na imensa escala que se estende por toda a história da cultura, desde as fantasias do nômade selvagem até as reflexões do filósofo moderno, encontra-se uma infinidade de versões da utopia. (SWIETOCHOWSKI, apud SZACHI, 1972, p. 8).
}

Refletindo sobre esse pensamento, é como se as utopias existentes nas diversas épocas da humanidade fossem suas filhas legítimas (SZACHI, 1972). Entre os diferentes tipos de utopia existentes, Szachi (1972) estabelece uma divisão de dois grandes grupos para caracterizálas: utopias escapistas e utopias heroicas. No caso das utopias escapistas, como o autor classifica a obra de Morus (2004), apesar de apresentarem uma crítica contra a realidade, não organizam um caminho para uma mudança da sociedade. Não existe nelas um programa pragmático que determina a renovação da estrutura social, "mas constroem em suas obras um espaço de libertação e de devaneio individual" (PAVLOSKI, 2005, p. 38). Já as utopias heroicas estruturam um plano de ação 
visando às transformações objetivadas ao longo da narrativa. Além de revolucionários, os planos "preveem a reestruturação profunda dos padrões políticos, econômicos, morais e ideológicos que regem uma sociedade particular" (PAVLOSKI, 2005, p. 39).

A ilha da República de Utopia criada por Morus (2004), assim como muitas outras utopias escapistas ${ }^{7}$, é centrada na ideia de um espaço diferente, onde uma localidade imaginária não remete somente à distância geográfica, mas também a costumes, modos de agir e estruturas sociais. Soma-se então a representação de uma sociedade ideal a esse objetivo de fuga da realidade trazida com as obras utópicas, onde é dada ao indivíduo a possibilidade de condenar o presente, mas sem enfrentá-lo. Ainda nas palavras de Szachi (1972, p. 23): "Dizse o que é o bem, mas não se diz como alcançá-lo. Diz-se em que consiste o mal, mas não se diz como substituí-lo pelo bem”. Morus (2004), ao longo da narrativa, deixou transparecer, mesmo que de forma subjetiva, a crítica de que seus desejos para o que chamava de sociedade ideal não seriam possíveis, muito em função das práticas do sistema vigente da época. É ele a dizer: "Contudo, devo confessar que há muita coisa na República de Utopia que eu desejaria ver imitada em nossas cidades - coisa que mais desejo do que espero" (MORUS, 2004, p. 131).

Antes uma fuga da realidade para o lugar ideal, a crítica social feita por meio dessa obra dá lugar para representações mais enérgicas. Com o passar dos séculos e a emergência de novas potências mundiais, a intensificação das disputas de poder e territórios, principalmente através de guerras, o otimismo por um "lugar melhor" começou a ser derrubado. Nunca haviam acontecido guerras mundiais, que envolvessem todas as potências, ao invés de se concentrar em batalhas unilaterais. Hobsbawm (1995) destaca que foi a partir de 1914, com a eclosão da Primeira Guerra Mundial, que um conflito envolveu todas as grandes potências e as tropas do ultramar foram enviadas para lutar e operar além de seus limites. Segundo o autor, foram 31 anos de conflitos ao redor do mundo que culminaram na morte de milhões de pessoas, através do uso dos mais diferentes tipos de armamentos pesados e de destruição em massa, como a bomba nuclear. Em suas palavras:

(...) quatro dias após a explosão da primeira bomba nuclear - em que o fim de considerável proporção da raça humana não pareceu muito distante. (...) A humanidade sobreviveu. (...) Não há como compreender o Breve Século XX sem ela. Ele foi marcado pela guerra. (HOBSBAWM, 1995, pp. 24-25).

O período entre guerras (1918-1939) foi marcado pela Grande Depressão e a quebra da Bolsa de Nova York, a ascensão dos regimes totalitários na Europa, tensões sociais e políticas, bem como o fim da hegemonia do capitalismo, dando espaço para a prática socialista na URSS. Em diversos momentos ao longo das disputas, o fim da
7 Como exemplo de utopias escapistas que trazem a ideia de um novo espaço imaginário, podemos citar A Nova Atlântida, de Francis

Bacon (1627), e As Viagens de Gulliver, de Jonathan Swift (1726). 
humanidade era visto como próximo, em função das mortes e destruições provocadas, principalmente, durante a Segunda Guerra Mundial. Mas, com o início da Guerra Fria, as tensões se intensificaram ainda mais, dando indícios de um conflito iminente. Diante desse cenário, começa a crescer o pensamento distópico. Contrário à utopia, ele não pensa no futuro como uma sociedade perfeita, mas, sim, muito pior do que a que é vivida no tempo presente.

Pavloski (2005) associa a ascensão do gênero distópico na literatura, em detrimento da utopia, à revolução comunista na Rússia e à ascensão do fascismo na Europa, somados à invasão dos conceitos e técnicas da ficção científica, uma vez que eles geram uma potencialização negativa da sociedade. Segundo o autor,

\footnotetext{
No contexto de constante renovação técnica e, consequentemente, social, as distopias começam a ocupar um espaço de destaque somente no século XX, sendo a revolução comunista na Rússia e a ascensão do fascismo na Itália, Alemanha e Espanha apontadas como determinantes do florescimento da literatura distópica em detrimento dos ideais utópicos. A mudança de utopia para distopia envolve precisamente a invasão do utopismo tradicional pelos conceitos e técnicas da ficção científica. Ocorre uma potencialização negativa das sociedades modelares - o que as torna repelentes por envolver a imposição da ordem à custa da liberdade - em projeções que nos forçam a enfrentar as implicações das utopias de modo mais concreto e, consequentemente, mais agudo. (PAVLOSKI, 2005, p. 63).
}

A distopia, como gênero literário, torna-se então "a denúncia dos efeitos de poder ligados às formas discursivas" (HILARIO, 2013 , p. 206). Ela transfere para a narrativa os medos e ansiedades da sociedade em relação ao futuro que surgem no início do século $\mathrm{XX}$, principalmente, no que tange à presença da tecnologia, que começa cada vez mais a determinar estilos de vida, produção e dominação, e da materialização das utopias, que saem do 'papel' e começam a ganhar formas de organização da sociedade (KOPP, 2011). Essas questões, amplamente abordadas nas obras iniciais do pensamento distópico, personificam o "temor quanto ao destino do homem diante de um novo mundo que pode conduzi-lo a ser um outro homem, um homem transformado" (KOPP, 2011, p. 52).

Trazendo uma imagem de um futuro ameaçador, onde o estado totalitário domina a sociedade, as distopias têm como suporte ao controle e poder um grande aparato tecnológico. De acordo com Kopp (2011), existe uma questão acerca da tecnologia nas narrativas distópicas trazida por Beauchamp (1986): se ela seria apenas um mecanismo nas mãos dos sistemas totalitários, de modo a facilitar o controle e o poder, ou se a tecnologia teria condições de sozinha, atingir tamanha autonomia para modificar a sociedade e fazê-la subserviente às suas intenções. Nesse ponto, Beauchamp (1986) destaca a presença de duas correntes que discutem o tema: os tecnófilos e os tecnofóbicos: 

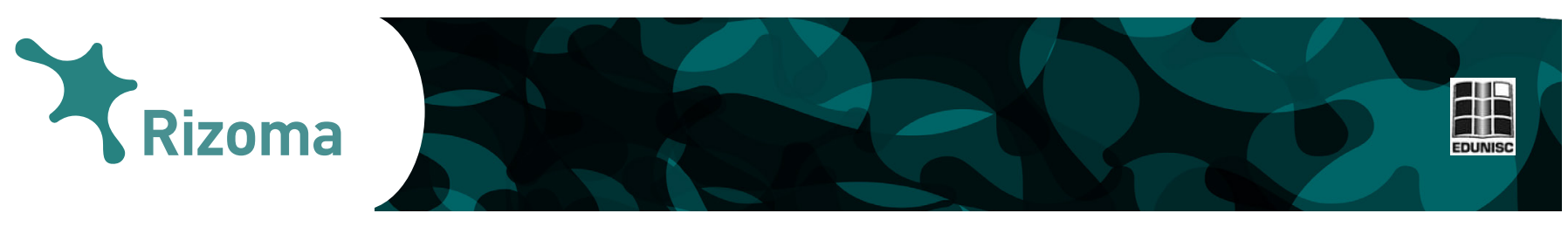

\begin{abstract}
Os primeiros veriam a tecnologia como um valor neutro, um instrumento capaz de ser usado para os fins os quais o humano se inclinar a fazer. Por outro lado, os tecnofóbicos acreditam que a tecnologia pode vir a transcender os propósitos criados inicialmente e pode adquirir independência, numa espécie de relação ao modo do que foi imaginado por Mary Shelley, em Frankenstein (1831). Esta percepção tecnofóbica é a que define, em seu ponto de vista, a maioria das ficções distópicas, revelando a tecnologia como um monstro moderno capaz de ser totalitária em si mesma e não apenas um caminho para facilitar a ordenação e o controle da sociedade. (BEAUCHAMP, apud KOPP, 2011, p. 51)
\end{abstract}

Esse contexto permanece no século XXI e, com as mudanças trazidas para a sociedade com o início deste século e o fim do período da Guerra Fria (HOBSBAWM, 1995), pode ser observado a partir dos ataques de 11 de setembro de 2001, que destacaram a vulnerabilidade dos EUA aos ataques terroristas. Segundo Phaar e Clark (2012), foi justamente após os ataques que as obras de distopia voltaram a explodir, agora no século XXI. De acordo com os autores:

\footnotetext{
Romances distópicos e pós-apocalípticos parecem evocar e liberar a mentalidade de medo e isolamento sentido por muitas pessoas do mundo real depois dos ataques ao Pentágono e ao World Trade Center. Certamente, muitas crianças crescendo após 11/9 podem sentir menos confiança em relação a sua segurança pessoal que as gerações que vieram antes. E mesmo aqueles que possuem forte suporte pessoal podem sentir uma erosão paralela na confiança dos adultos que, supostamente, controlam o mundo. (PHAAR; CLARK, 2012, p. 08).
}

Assim, as obras distópicas, novamente, surgem em um contexto de incerteza e descrença nas dimensões política, social e econômica, onde o futuro passa a ser enxergado, mais uma vez, com um olhar negativo. As distopias, portanto, refletem tanto o que a sociedade espera do futuro, como também aquilo que ela experimenta em sua própria vida cotidiana.

\title{
Fiç̧ão distópica como crítica e reflexo do cotidiano
}

Ao trabalhar o conceito de cotidiano, Heller (2000, p. 17) afirma que "a vida cotidiana é a vida do homem inteiro; ou seja, o homem participa na vida cotidiana com todos os aspectos de sua individualidade, de sua personalidade". Assim, o cotidiano é heterogêneo e os diversos aspectos e núcleos diferentes que o orbitam ocupam lugares de forma hierárquica para cada indivíduo. Como o homem utiliza todas as suas capacidades simultaneamente, nenhuma delas será exercida em sua potência máxima. Além do mais, a vida cotidiana é regida pelo imediatismo, sem uma grande distância entre o intervalo de tempo do pensamento e da ação.

Por fazer do mundo um ambiente imediato, o homem muitas vezes trabalha com a imitação. Assim, cada indivíduo irá se reproduzir como 

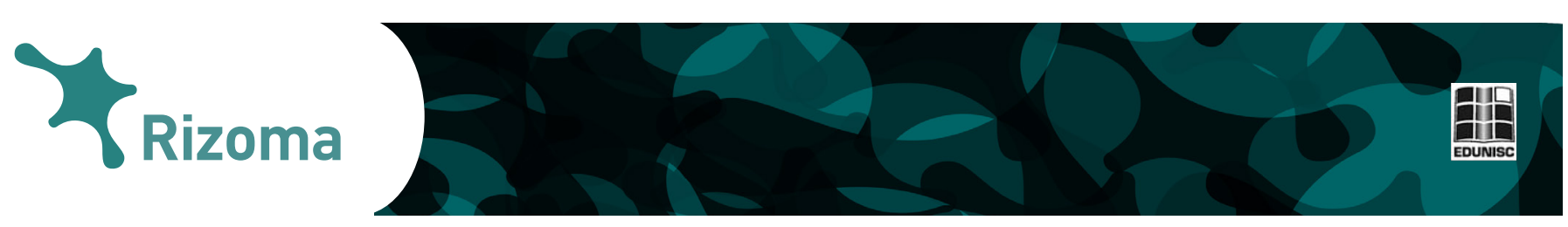

indivíduo único e também, indiretamente, como totalidade social - as possibilidades de reprodução social que permitem a mimese e o imediatismo no cotidiano. "O homemé, ao mesmo tempo, singular e genérico. Apenas, na vida cotidiana, este ser genérico, coparticipante do coletivo, da humanidade, se encontra em potência, nem sempre realizável. Na vida cotidiana só se percebe o singular" (CARVALHO; NETTO, 2007, p. 26).

Desta maneira, de acordo com Heller (2000), a vida cotidiana é aquela que mais se presta à alienação. De toda forma, ela não é necessariamente de todo alienada, pois ainda há espaço para explicitação e movimento contra o fluxo alienante. Porém, "quanto maior for a alienação produzida pela estrutura econômica de uma sociedade dada, tanto mais a vida cotidiana irradiará sua própria alienação para as demais esferas" (HELLER, 2000, p. 38). Pode-se afirmar, portanto, que uma forma de suspensão da cotidianidade é através da homogeneização, uma objetivação que realiza a passagem do "homem inteiro (muda relação de sua particularidade e 'genericidade') para o inteiramente homem (unidade consciente do particular e do genérico)" (HELLER, 2000, p. 38). Essa suspensão pode ser realizada, de acordo com a autora, através do trabalho, da arte, da ciência e da moral.

Na obra 1984, de George Orwell, por exemplo, indivíduos encontram-se alienados em sua cotidianidade através dos próprios mecanismos de poder e controle do estado autoritário e vigilante. $\mathrm{O}$ livro se passa em um contexto de guerra constante, no qual a Oceania vive um regime ditatorial presidido pelo Grande Irmão, figura máxima do grande partido, que sempre "está de olho em você". Assim, todos os atos de cada indivíduo são controlados pelo estado, que insere a sociedade em uma lógica da violência, da burocracia e da miséria. Não há suspensão de tal cotidianidade e, quando há qualquer tentativa, a mesma é apagada pelo regime, que não só repreende qualquer ato que vá contra seus princípios como também reescreve a própria história, borrando todo passado que pudesse abalar o presente. Winston Smith, personagem principal do livro, busca uma espécie de suspensão da alienação ao qual é subordinado, mas até mesmo suas tentativas são, ao fim, tolhidas e reprimidas, fadadas ao silêncio.

Dessa forma, 1984 pode, em teoria, representar uma espécie de projeção do futuro distópico para o qual a sociedade poderia caminhar, mas é uma obra que se insere também naquilo que o autor e a sociedade presenciava no seu momento de escrita e em sua cotidianidade. O ano de 1949, no qual o livro foi lançado, e o contexto da Inglaterra, terra natal de Orwell, e de toda a Europa são estopins para que obras distópicas passassem a figurar no imaginário literário. Bem diferente da utopia positivista de Thomas Morus, as novas "utopias negativas" do século XX representam a desesperança com o futuro, em parte por conta do contexto das Grandes Guerras, da crise econômica iniciada em 1929 e da falência de regimes socialistas da União Soviética, conforme abordado anteriormente neste artigo. 


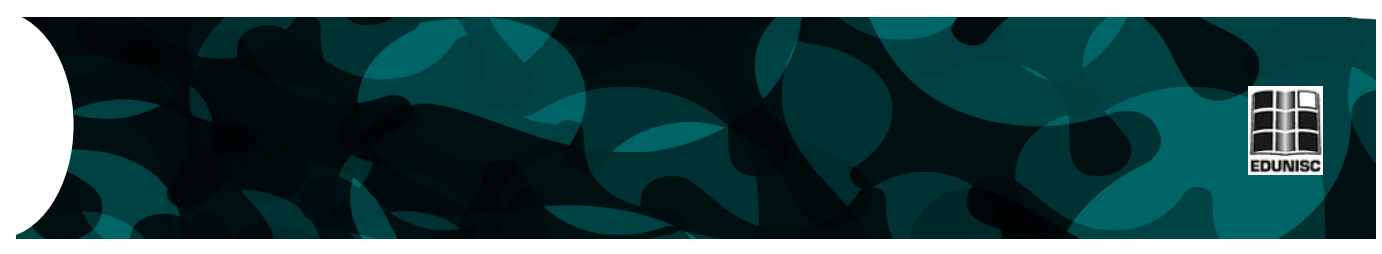

Além de 1984, a obra Nós, escrita pelo russo Yevgeny Zamyatin entre 1920 e 1921, também expressa certa descrença com um futuro pós-guerra. Escrito poucos anos após a Revolução Russa 1917, quando os bolcheviques tomaram o poder, Nós reflete em suas páginas a instabilidade política e social da Rússia nos primeiros anos depois da queda do antigo regime czarista. A partir da representação de uma sociedade que vive aproximadamente 900 anos após o século XX, Nós apresenta logo de início o narrador da história, o personagem D-503 - em Nós, os indivíduos possuem um código de identificação, e não um nome - que não cansa de descrever a perfeição da vida e da sociedade daquela época - esta descrição está diretamente ligada à diegese narrativa, já que se trata de registros históricos apontados pelo narrador. A suposta utopia presente no início da trama começa a se corromper quando uma personagem, I-330 - corruptora do sistema, atravessa o caminho de D-503 e este começa a questionar sua total obediência ao Estado Único - este é o nome do estado-ditadura que controla todos os indivíduos.

Em Nós, assim como em 1984, todos os indivíduos são monitorados vinte e quatro horas por dia; além disso, têm suas ações completamente cronometradas de forma precisa. A ordem, em Nós, é o equilíbrio absoluto, o contrário do caos em que viviam as sociedades no século $\mathrm{XX}^{8}$; a matemática é o saber supremo, já que esta instaura a ordem em sua mais perfeita harmonia, aplicando-se, diretamente, inclusive aos atos artísticos e criativos, como na composição musical. Como afirma D-503 em certa passagem do texto:

Que grande prazer o meu ao escutar depois a nossa música contemporânea (...) Os acordes breves das fórmulas de Taylor, de McLaren; as passagens sonoras, quadradas, do teorema de Pitágoras (...) Quanta grandeza! Que regularidade inflexível! Que limitada era a música dos antigos, sem mais restrições do que as de uma fantasia bárbara. (ZAMYATIN, epub, pp. 17-18).

Mesmo que expressando essa desesperança com o que as sociedades passavam a vivenciar a partir da modernidade e do capitalismo, Orwell (2010) e Zamyatin ainda enxergavam o que Heller (2000), ao conceituar o próprio cotidiano, chama de suspensão da cotidianidade a consciência de um estado para além da uniformidade e imediatismo da vida cotidiana. Em posfácio escrito para a obra de George Orwell, Fromm (1961, p. 370), ao abordar as obras distópicas do século XX, questiona esse aspecto comum às "utopias negativas":

A questão é filosófica, antropológica e psicológica, e talvez também religiosa. É a seguinte: pode a natureza humana ser modificada de tal maneira que o homem esquecesse seu desejo de liberdade, dignidade, integridade, amor - ou seja, pode o homem esquecer que é humano? Ou tem a natureza humana uma dinâmica que reagiria à violação dessas necessidades humanas básicas com a tentativa de transformar uma sociedade inumana numa sociedade humana? (FROMM, 1961, p. 370). 


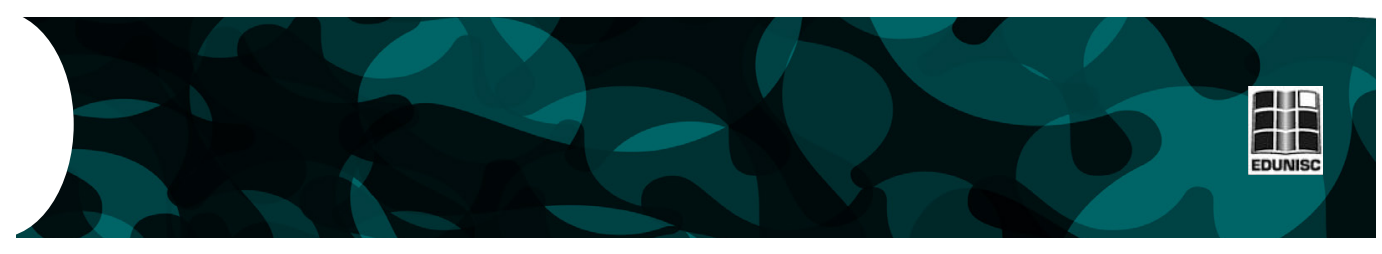

Assim, tanto em 1984 quanto em Nós, os personagens buscam o que Heller (2000) chama de homogeneização, ou seja, a percepção da unidade consciente e genérica a todos os homens - algo próximo ao que Fromm coloca em seu posfácio com o que chama de sociedade humana.

De forma análoga, Michel de Certeau propõe o que ele chama de táticas como forma de subversão de regras a partir de certas práticas do cotidiano. De acordo com o pensador francês, são elas que possibilitam a vitória do fraco sobre o forte - sobre o sistema, o estabelecido, o configurado - a partir da apropriação das forças que lhe escapam; de certa forma a partir do uso da força do sistema contra o próprio sistema. Nas palavras de Certeau (1998, p. 47), "ele o consegue em momentos oportunos onde combina elementos heterogêneos (...), mas a sua síntese intelectual tem por forma não um discurso, mas a própria decisão, ato e maneira de aproveitar a 'ocasião"'. Podemos verificar o emprego de tais táticas em Nós, quando a personagem I-330 começa um processo de aproximação do narrador e protagonista, D-503, a fim de "encantá-lo", no intuito de alcançar seu objetivo: o desmonte do regime totalitário descrito na trama. Busca-se a subversão do próprio sistema, a partir de dentro. Ou ainda, em 1984, quando Winston passa a viver um romance com Julia e ambos sonham com uma revolução vinda dos "proletas", os trabalhadores "que não haviam aprendido a pensar, mas que acumulavam em seus corações, ventres e músculos a força que um dia subverteria o mundo" (ORWELL, 2010, p. 259). Ocorre o mesmo Jogos Vorazes, quando a personagem principal, Katniss Everdeen, simula um sentimento romântico em direção a Peeta, para que ambos pudessem sair vivos da arena de batalha. São práticas do cotidiano, artes do fazer, no dizer de Certeau (1998), que pretendem implodir estruturas cristalizadas e normatizadas.

Além de seguir a proposta de uma sociedade distópica, a obra Jogos Vorazes, de Suzanne Collins, é concebida em meio a um cenário de subserviência e medo, onde a população é tolhida de seus direitos e obrigada a assistir aos "espetáculos" dos Jogos Vorazes. Na narrativa, os 12 distritos de Panem estão prestes a participar da $74^{\mathrm{a}}$ edição dos Jogos. Todos os jovens, de 12 a 18 anos são obrigados a colocar seu nome na Colheita, cerimônia que vai escolher a dupla representante nos jogos. Faz parte do cotidiano de cada um dos distritos viver sob a pressão da Capital. Não existe liberdade, mas, sim, uma coerção da Capital sobre cada um deles, incluindo os mais ricos.

A alienação dos habitantes de Panem começa com a obrigatoriedade de produção para atender aos interesses da Capital. Cada distrito é responsável por um tipo de produção: ouro e pedras preciosas (1), alvenaria (2), tecnologia (3), pescaria (4), energia (5), transportes (6), madeira (7), têxteis (8), grãos (9), pecuária (10), agricultura (11) e mineração (12). Eles não se comunicam entre si e não sabem o que acontece no dia a dia do outro, tendo acesso apenas ao que é televisionado pelo único canal fornecido pela Capital. 

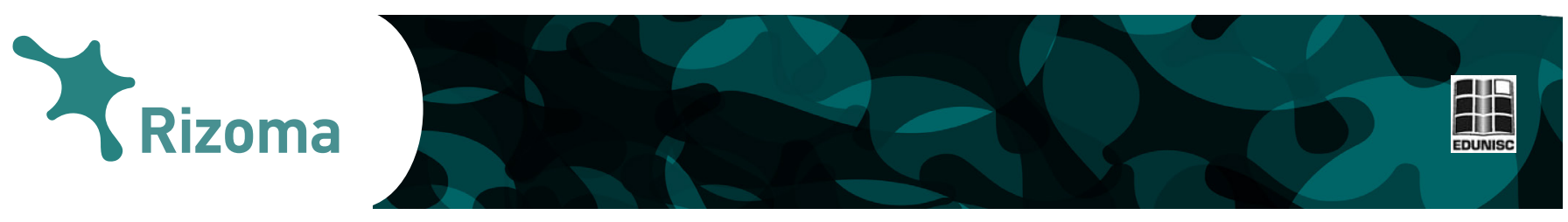

No mundo de Panem, é fácil perceber traços da América contemporânea. Por exemplo, a nossa atual obsessão com reality shows, arte corporal e consumismo em massa estão todos claramente expressos nessa sociedade futura. Até mesmo nossa contínua vontade de empreender guerras e o crescente custo emocional desse comportamento estão tecidos no fio narrativo dos restos dessa América quase futura. (GANT, 2012, p. 89). ${ }^{9}$

Dessa maneira, ao levar para a narrativa a ideia de televisionar assassinatos triviais como forma de entretenimento e dominação, Collins (2010) também acaba por fazer uma analogia com a sociedade atual. A narrativa distópica apresenta um tempo histórico que emerge ao longo do texto, de modo a apresentar estruturas históricas de compreensão. Mas, apesar disso, esse mesmo tempo é anti-histórico. Isso pode ser explicado através da existência de um espaço ficcional, que é real, geograficamente falando, mas que é rearranjado no universo ficcional. Em Jogos Vorazes, por exemplo, a narrativa se passa em uma América do Norte pós-apocalíptica, que foi destruída após uma série de desastres climáticos. Essa organização do discurso narrativo, que compreende a relação entre narrativa e história, pode-se explicar justamente como uma coordenação temporal da narratividade através do tempo histórico.

Segundo White (1984), isso acontece em decorrência de uma modalidade humana da consciência do tempo, onde um evento especificamente histórico não é algo que possa ser inserido de qualquer forma em uma história de acordo com o desejo do autor.

\footnotetext{
(...) é antes um tipo de evento que pode "contribuir" para o "desenvolvimento de um enredo". É como se o enredo estivesse em processo de desenvolvimento antes da ocorrência de qualquer evento, e qualquer evento poderia ser dotado de "historicidade" apenas na medida em que poderia ser mostrado em contribuir para este processo. E, de fato, tal parece ser o caso, porque para Ricouer "historicidade" é um modo estrutural ou nível de “temporalidade” em si. (WHITE, 1984, p. 27, tradução nossa). ${ }^{10}$
}

Essa relação temporal entre presente, passado e futuro é um dos principais elementos da narrativa, uma vez que a existência do tempo ficcional só encontra um mínimo de explicação racional se levada em consideração a realidade da temporalidade humana (CARVALHO, 2010), abrindo espaço para concepções de tempo que ultrapassam meramente a dimensão cronológica, como as psicológicas, por exemplo. É a realidade humana que permite compreender as alterações do tempo, seja em distensões ou em sua finitude. $\mathrm{O}$ autor destaca ainda a característica do tempo como parte da memória da humanidade, sendo o que possibilita resgatar o passado e também prever possibilidades para o futuro.

Nesse ponto, sobre as projeções acerca de um futuro desconhecido, resgate do passado ou até mesmo para fixar as noções do tempo presente, é que Ricoeur (1994, pp. 25-26) atribui a importância da narrativa.
9 "In the world of Panem, it's easy to see traces of contemporary America. For example, our current obsession with reality $\mathrm{TV}$, body art, and mass consumerism are all clearly extrapolated in this future society. Even our recurring and ongoing willingness to wage war and the growing emotional cost of that behavior are woven into the thread of this near-future remnant of America."

10 " ....it is rather a kind of event that can 'contribute' to 'the developement of a plot'. It is as if the plot were anentity in process of development prior to the occurrence of any given event, and any given event could be endowed with 'historicality' only in the extent to which it could be shown at contribute to this process. And, indeed, such seems to be the case, because for Ricoeur'historicality' is a structural mode or level of temporality' itself".

Em nome de que proferir o direito de o passado e o futuro serem de algum modo? Ainda uma vez, em nome do que dizemos e fazemos a propósito 


\section{Y.izoma}

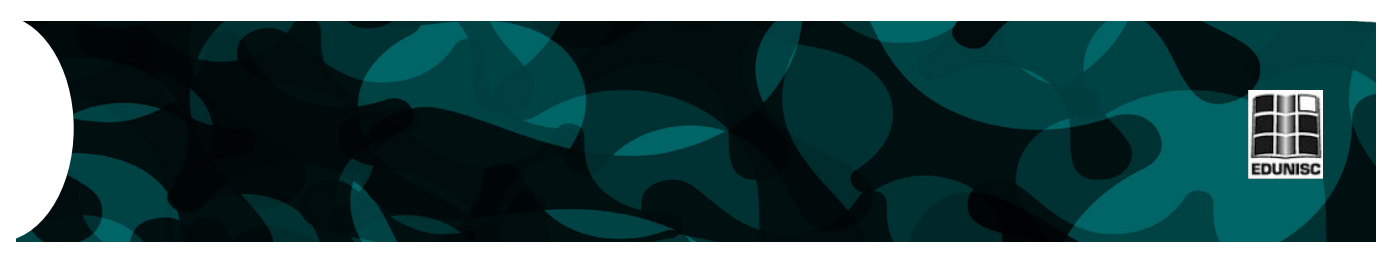

deles. Ora, o que dizemos e fazemos quanto a isso? Narramos as coisas que consideramos verdadeiras e predizemos acontecimentos que ocorrem tal como havíamos antecipado. É pois sempre a linguagem, assim como a experiência, a ação, que esta articula, que resiste ao assalto dos céticos. Ora, predizer é prever e narrar é "discernir pelo espírito".

A essa intriga do tempo, que Ricoeur(1994) remeteà obra aristotélica Poética e suas considerações temporais sobre início, meio e fim, surgem as próprias considerações do autor sobre a tríplice mimética existente na mediação entre o tempo e a narrativa. A mimese, muito além da imitação, tem como papel tornar concreta a narrativa, o ato de narrar. Em uma síntese de Carvalho (2010), entende-se como mimese I a representação das dimensões éticas, o mundo social e sua complexidade; mimese II como o ato de configuração, onde existe a presença de um narrador e, simultaneamente, onde ocorre a mediação entre a mimese I e mimese III que, por sua vez, diz respeito à reconfiguração, com presença ativa do leitor ${ }^{11}$. Com isso, torna-se possível então compreender a existência de temas históricos nas narrativas distópicas com o intuito de contribuir para o contexto e espaço ficcional desenhados nas tramas distópicas.

O diálogo existente nas obras narrativas - aqui, exemplificadas através do gênero distópico - entre literatura e história é visto como um jogo transdisciplinar e interdiscursivo que envolve as diferentes formas de conhecimento sobre o mundo (PESAVENTO, 2006, p. 6), onde, ainda segundo a autora, "a história pergunta e a literatura responde". Associar narrativas como as aqui apresentadas - Nós, 1984 e Jogos Vorazes - com temas pertinentes nas discussões da atualidade torna-se então possível a partir da atemporalidade do gênero narrativo. Nas palavras da autora:

\footnotetext{
A verdade da ficção literária não está, pois, em revelar a existência real de personagens e fatos narrados, mas em possibilitar a leitura das questões em jogo numa temporalidade dada. $\mathrm{O}$ texto literário revela e insinua as verdades da representação ou do simbólico através de fatos criados pela ficção. Mais do que isso, o texto literário é expressão ou sintoma de formas de pensar e agir. (PESAVENTO, 2006, p. 7).
}

Uma vez que ela não tem um tempo datado, a narrativa consegue aproveitar a história para criar um entendimento lógico com o leitor/ espectador, mesmo que apresente um universo distanciado e fantasioso em um primeiro momento.

\section{Conclusão}

Nós, 1984 e Jogos Vorazes são obras que trabalham a ideia de um futuro distópico, mas que, paralelamente, realizam um retrato da sociedade no momento em que se inserem. A retomada de tais obras, com o apelo para um público jovem/adolescente, mostra que o momento de crise econômica e política transforma nossa percepção
${ }^{11}$ A questão sobre a presença ativa leitor será aprofundada no tópico seguinte. 
sobre o futuro a partir de uma "utopia negativa". O diálogo existente entre a literatura e a história pode ser compreendido como uma resposta aos anseios da sociedade que são respondidos por meio da trama das narrativas.

Cabe ressaltar aqui que esta discussão vai além da proposta neste artigo. Poderíamos abordar, por exemplo, o quanto o biopoder, no sistema capitalista, subjuga nossos corpos e nossa própria percepção acerca do futuro. O recado é simples: após o capitalismo, só há a distopia. E as obras de ficção distópicas parecem refletir essa forma de pensamento acerca do futuro, ou seja, a representação de uma sociedade distópica como uma estratégia de dominação, onde não há um horizonte nem final feliz após o fim do capitalismo. "Para nós é fácil imaginar o fim do mundo - vide os inúmeros filmes apocalípticos -, mas não o fim do capitalismo" (ZIZEK, 2011, p.).

\section{Referências}

BRAVO! Distopia e Realidade. 2016. Disponível em: http://bravo. $\mathrm{vc} / \mathrm{s} 0$-incertitude/e2-distopia-realidade/?platform=hootsuite/. Acesso em: DIA dez 2016.

CARVAlHO, M. C. B.; NETTO, J. P. Cotidiano: Conhecimento e crítica. São Paulo: Cortez Editora, 2007.

CARVALHO, Carlos Alberto de. A tríplice mimese de Paul Ricoeur como fundamento para o processo de mediação jornalística. In: ENCONTRO DA COMPÓS, 19., 2010, Rio de Janeiro. Anais... Rio de Janeiro: Compós, 2010. Disponível em http://compos.com.puc-rio. br/media/gt9_carlos_\%20alberto_carvalho.pdf

CERTEAU, Michel de. A invenção do cotidiano: artes do fazer. 3. ed. Trad. Ephraim Ferreira Alves. Petrópolis/RJ: Editora Vozes, 1998.

COLLINS, Suzanne. Jogos Vorazes. Rio de Janeiro: Rocco Jovens Leitores, 2010.

GANT, Tammy L. Hungering for Righteousness: Music, Spirituality and Katniss Everdeen. In: PHARR, M. F.; CLARK, L. A(Eds.). Bread, Blood and The Hunger Games: Critical Essays on the Suzanne Collins Trilogy. Jefferson: Macfarland, 2012.

HELLER, Agnes. O Cotidiano e a História. São Paulo: Editora Paz e Terra, 2000. 
HILÁRIO, Leomir. Teoria crítica e literatura: A distopia como ferramenta de análise radical da modernidade. Anuário de Literatura, Florianópolis, v. 18, n. 2, 2013. Disponível em: http:// dx.doi.org/10.5007/2175-7917.2013v18n2p201/. Acesso em:

HOBSBAWM, Eric. Era dos Extremos: O breve século XX. São Paulo: Companhia das Letras, 1995.

KELLNER, Douglas. O apocalipse social no cinema contemporâneo de Hollywood. Matrizes, São Paulo, v. 10, n. 1, p. 13-28, 2016. Disponível em: http://www.matrizes.usp.br/index.php/matrizes/ article/viewFile/735/pdf/. Acesso em:

KOPP, Rudinei. Comunicação e mídia da literatura distópica de meados do século 20: Zamiatin, Huxley, Orwell, Vonnegut e Bradbury. 2011. 278 f. Tese (Programa de Pós-Graduação em Comunicação - Mestrado e Doutorado) - Faculdade de Comunicação Social, Pontifícia Universidade Católica do Rio Grande do Sul, Porto Alegre, 2011.

MORUS, Thomas. A utopia. Brasília: Editora Universidade de Brasília, 2004.

NEXO. Realidade ou ficção distópica? Você sabe diferenciar? 05 dez. 2016. Disponível em: https://www.nexojornal.com.br/ interativo/2016/12/05/Realidade-ou-fic $\% \mathrm{C} 3 \% \mathrm{~A} 7 \% \mathrm{C} 3 \% \mathrm{~A} 3 \mathrm{o}-$ dist $\% \mathrm{C} 3 \%$ B3 pica-voc $\% \mathrm{C} 3 \% \mathrm{AA}-$ sabe-diferenciar/. Acesso em: DIA dez. 2016.

ORWELL, George. 1984. São Paulo: Companhia das Letras, 2010.

PAVLOSKI, Evanir. A distopia do indivíduo sob controle. 2005. 274 f. Dissertação (Programa de Pós-Graduação em Letras - Mestrado) Universidade Federal do Paraná, Curitiba, 2005.

PESAVENTO, Sandra. História \& Literatura: uma velha-nova história. Nuevo Mundo Mundos Nuevos [Enligne], Débats, mis enlignele 28 janvier 2006, consultéle 28 mars 2017. URL : http:// nuevomundo.revues.org/1560 ; DOI : 10.4000/nuevomundo. 1560

PHARR, M. F.; CLARK, L. A. (Eds.). Bread and blood and The Hunger Games: Critical Essays on the Suzanne Collins Trilogy. Jefferson: MacFarland, 2012.

RICOEUR, Paul. Tempo e Narrativa - Tomo I. Campinas: Papirus, 1994. 

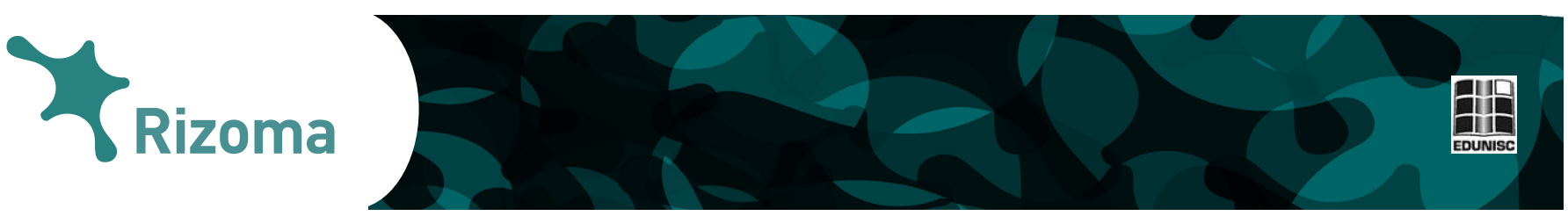

SZACHI, Jerzy. As Utopias ou a Felicidade Imaginada. Rio de Janeiro: Paz e Terra, 1972.

WHITE, Hayden. The question of narrative in contemporary historical theory. In: HistoryandTheory. 23/1 (1984): pp. 1,33.

ZAMYATIN, Yevgeny. Nós. Epub.

ZIZEK, Slavoj. A tinta vermelha: discurso de Zizek no Occupy Wall Street. Disponível em: <https://blogdaboitempo.com.br/2011/10/11/ a-tinta-vermelha-discurso-de-slavoj-zizek-aos-manifestantes-domovimento-occupy-wall-street> Acesso em: 31 de maio de 2017. 